\title{
DEVELOPING SIMULATION-BASED DECISION SUPPORT SYSTEMS FOR CUSTOMER- DRIVEN MANUFACTURING OPERATION PLANNING
}

\author{
Juhani Heilala \\ Jari Montonen \\ Paula Järvinen \\ Sauli Kivikunnas \\ VTT Technical Research Centre of Finland \\ Metallimiehenkuja 6, P.O. Box 1000, \\ FI-02044 VTT (Espoo) FINLAND
}

\author{
Matti Maantila \\ Jarkko Sillanpää \\ Tero Jokinen
}

\author{
Oras Ltd \\ Isometsäntie 2, P.O. Box 40 \\ FI-26101 Rauma FINLAND
}

\begin{abstract}
Discrete-event simulation (DES) has mainly been used as a production system analysis tool to evaluate new production system concepts, layout and control logic. Recent developments have made DES models feasible for use in the day-to-day operational production and planning of manufacturing facilities. Operative simulation models provide manufacturers with the ability to evaluate the capacity of the system for new orders, unforeseen events such as equipment downtime, and changes in operations. A simulationbased Decision Support System (DSS) can be used to help planners and schedulers organize production more efficiently in the turbulent global manufacturing. This paper presents the challenges for development and the efforts to overcome these challenges for the simulation-based DSS. The major challenges are: 1) data integration 2) automated simulation model creation and updates and 3) the visualization of results for interactive and effective decision making. A recent case study is also presented.
\end{abstract}

\section{INTRODUCTION}

Agile, fast and flexible production networks are a must for companies facing today's global competition. The connections between manufacturing systems and processes are becoming more complex and the amount of data required for decision-making is growing. In order to make decisions related to manufacturing, engineering and production management, multiple parameters must be considered. Agile production requires a management and evaluation tool for changes to production, manufacturing system development, configuration and operations planning. As shown in this study, a Decision Support System (DSS) based on manufacturing simulation is one suitable solution.

Delivering on the stated order date is a key element in customer satisfaction. One of the important decisions in production planning is the scheduling and synchronization of activities, resources and material flow. Old static production planning methods are not adequate; production planners need accurate and dynamic models of production, i.e. a simulation model that uses a production network and real shop floor data in near real-time.

Given the current global competition and in lean and agile manufacturing, material stocks are kept as small as possible, while expensive resource utilization should be kept as high as possible. Production personnel must seek a balance between customer orders and limited resources. Every new order upsets the current balance (Figure 1.). 
Heilala, Montonen, Järvinen, Kivikunnas, Maantila, Sillanpää and Jokinen

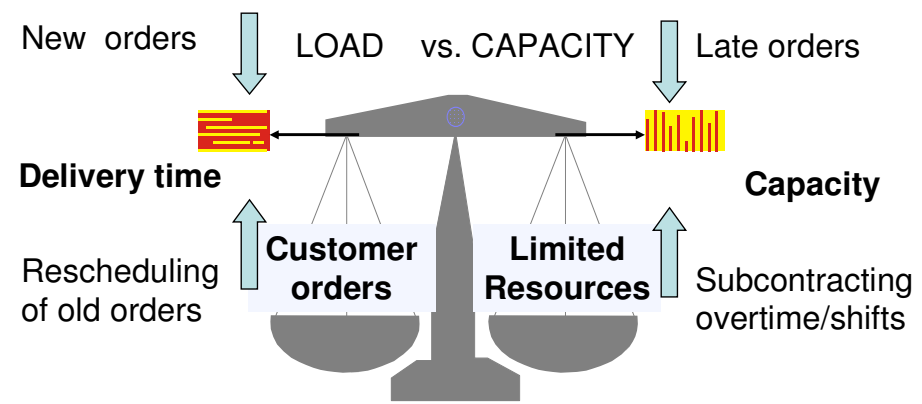

Figure 1: Balancing production between orders and limited resources.

In this complex world, decision support for human operators and information management is a key asset in managing "better-faster-cheaper" competition. Simulation analysis with real data provides forecasts on the basis of the given input values. This gives production managers the time to react to potential problems and evaluate alternatives. It is possible to strike a better balance between multiple parallel customer orders and finite resources. Some of the benefits of implementing an operational simulation scheduling system include: less effort in planning day-to-day schedules, ensuring on time delivery for customer orders, synchronizing flow through the plant and minimizing set-ups/changeovers. In addition, these systems can provide early warnings of potential problems, check critical resources and materials, and, naturally, allows users to do a "what-if" scenario analysis to plan capacity.

\subsection{Decision-making with simulation in manufacturing}

A DSS is an interactive computer-based system or subsystem intended to help decision makers use communications technologies, data, documents, knowledge and/or models to identify and solve problems, complete decision process tasks, and make decisions. DSS is a general term for any computer application that enhances a person's or group's ability to make decisions (Power 2010).

There are multiple decision-making aims in the manufacturing system domain. Strategic and tactical aims focus on the design or selection of a new manufacturing system or on the improvement of the existing manufacturing system; the planning time horizon is years or months (Figure 2). Operational aims, which target the operations of the existing system, have a much shorter time frame - days, hours or minutes - to solve problems in manufacturing. Discrete-event simulation (DES) methods can be used to analyze all types of discrete manufacturing systems, from project shops to automated production and assembly lines, all the way to the supply chain.

\begin{tabular}{|c|c|}
\hline Years, months & days, hours, seconds \\
\hline \multicolumn{2}{|l|}{ Minimizing investment risk } \\
\hline Layout planning & Balancing production lines \\
\hline Finding and elimination bottlenecks & Exception handling \\
\hline \multicolumn{2}{|c|}{ Testing routing and control strategies } \\
\hline Buffer size and location optimization & Lead-time optimization \\
\hline \multicolumn{2}{|c|}{ Capacity calculation } \\
\hline \multicolumn{2}{|c|}{$\begin{array}{l}\text { Ensuring on-time delivery } \\
\text { Optimization of utilization }\end{array}$} \\
\hline
\end{tabular}

Figure 2: The planning horizon and aims in production engineering and management. 
Thompson (1993) came up with the idea of integrating simulation and real-time controls two decades ago. A review on simulation-based real-time decision-making for manufacturing automation systems is presented by Yoon and Shen (2006). Kádár et al. (2006) explain how to use DES to support production planning and schedule decisions. In general, the annual Winter Simulation conference (http://www.wintersim.org/) is a good source for finding ongoing research and development results.

The potential uses of simulation-aided decision support for production planning are shown in Figure 3. In operations planning, a validated and tested simulation model is a must, as it involves reliable, near real-time data for analysis. The challenges of manufacturing system simulation and modeling are discussed later in the text.

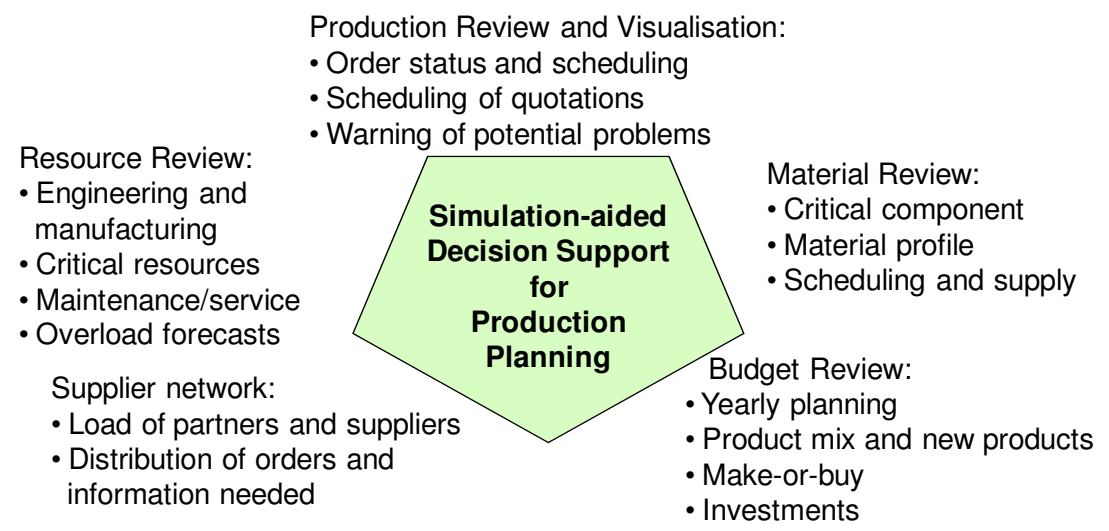

Figure 3: Potential use of simulation-aided decision support for production planning.

Many simulation-based scheduling and planning tools are currently being developed. Some of these tools have been presented by Hindle and Duffin (2006) and Vasudevan et al. (2008). There are many related software packages available, like Preactor (www.preactor.com ), Asprova (www.asprova.com ), and others made by simulation engineering offices, like Simul8-Planner (www.simul8-planner.com) and Delfoi Planner (www.delfoi.com/web/en_GB/).

The cheapest packages have fixed data structures and menus. This type of Gantt chart scheduling software targets users with the simple production scheduling problems typical of shops that do small jobs. Open source software from research institutes is available as well. Such software usually targets simpler production scheduling problems or is for educational use. More information is available at the Production Scheduling Portal (www.productionscheduling.com).

It is important to recognize that simulation primarily serves to support decision-making; it is used as an evaluation tool for feasible scheduling but its main aim is not to define optimal solutions. Optimization algorithms or scheduling rules can be embedded into the simulation model; in other cases, the system can combine optimization and simulation, as presented by Appelqvist and Lehtonen (2005) and Vasudevan et al. (2008).

The basic idea is to combine the strengths of automatic data analysis and the simulation results with the visual perception and analysis capabilities of the human user, i.e. the person responsible for making the final decisions. The use of simulation with an easy-to-use graphical user interface provides the tools and methods for manufacturing scenario evaluation, scheduling optimization, and production planning. These can even be used by people with little experience in simulations.

\subsection{Heterogeneous manufacturing information systems}

Manufacturing system operations are usually planned in a heterogeneous information system environment. There are business-oriented systems like Enterprise Resource Planning (ERP) - or Manufacturing Resource Planning (MPRII) or Material Requirements Planning (MRP) - Customer Relationship Man- 


\section{Heilala, Montonen, Järvinen, Kivikunnas, Maantila, Sillanpää and Jokinen}

agement (CRM), and facility-related systems like Enterprise Asset Management (EAM) and Maintenance Management System (MMS) as well as Product Data Management systems (PDM). Systems that can be used on the factory floor include a Manufacturing Execution System (MES), job shop data acquisition systems, quality control system, individual machine control systems and so on. A dedicated decision support system for manufacturing operations planning does not replace the existing systems; they remain in place as parallel systems, serving as sources of information for decision-making and provide the means to implement the decisions. Depending on the role of the DSS user, he or she may or may not have access to these other systems.

Existing ERP or MRP systems have some limitations; they are usually based on static resource models with unlimited capacity. At present, manufacturing scenarios cannot be studied efficiently with a standard ERP system.

The costs of integrating simulation systems with other manufacturing applications are high; there is always a need to transfer and share data between the simulation and other manufacturing software applications. Custom-built proprietary interfaces require extensive customization and when it comes to standardization, the current landscape for system integration is challenging.

\section{DEVELOPING A MODEL-DRIVEN DECISION SUPPORT SYSTEM}

\subsection{Challenges and research needs}

Manufacturing systems, processes and data are growing and becoming more complex. In order to make decisions on manufacturing engineering and production management, many interdependent factors and variables must be considered. These often complex, interdependent factors and variables are probably too many for the human mind to cope with at one time (McLean and Leong 2001). Simulation modeling and analysis could help in decision making. The IMTI Modeling and Simulation for Affordable Manufacturing Roadmap (IMTI 2003) defines 75 top-level goals and 250 supporting requirements for the research, development, and implementation of modeling and simulation technologies and capabilities. Another similar list of challenges is presented by Fowler and Rose (2004). Subsequent processing has distilled these needs into the following high-level goal: There is a need for permanent, always on, synchronized factory models or models that can be created automatically on-demand from ERP and other interoperable data sources and is used for manufacturing process and operation planning. Another common challenge is input data collection and management, as presented by Skoogh (2009).

\subsection{Real-time issues and data latency}

If managers are using a simulation model to plan operations, the model must be specific and updated regularly as stated above. Users need to be able to analyze "what-if" scenarios rapidly. The solution presented later in this paper is nearly a real-time solution, as there is some data latency. Data latency defines how current the information needs to be (Linthicum 2000).

- Real time: data is current, up-to-the second.

- Near time: data refers to information that is updated in set intervals rather than instantaneously.

- One time: data is typically updated only once or very rarely.

Some of the input files are "one time": only the modifications to the parameters are updated. Some other input files are "near time": the analysis can either be started by the user or is performed automatically at selected intervals. The case study presented later in this study uses the data from ERP and other manufacturing information systems: maintenance management data, machine utilization data and realtime work flow management data. 


\subsection{Potential for standardized neutral interfaces}

The use of standardized structured manufacturing data in a neutral format (like XML) could clearly increase interoperability between the manufacturing information system and the simulation, and also speed up modeling and problem solving cycles. Some of the potential standards are described here.

The Core Manufacturing Simulation Data (CMSD) specification (SISO 2009) is intended to define a neutral format for exchanging data between simulations and other manufacturing applications. The specification is defined as an information model using the Unified Modeling Language (UML) with a mapping to an exchangeable eXtensible Markup Language (XML) format. The test cases for draft CMSD specification can be found in Kibira and McLean (2007), Johansson et al. (2007), McLean et al. (2007) and Riddick and Lee (2008).

Other standardization efforts may also be useful in the future. For instance, ISA-95 (www.isa.org or www.isa-95.com) focuses on MES/ERP integration. MIMOSA (ww.mimosa.org) is developing and encouraging the adoption of open information standards for operations and maintenance in manufacturing and facility environments. The MIMOSA open standard enables collaborative asset lifecycle management. The MTConnect Institute (www.mtconnect.org) is designing an open communication standard for interconnectability in the manufacturing arena. The MTConnect standard allows devices and systems to send out understandable information. Similarly, AutomationML (www.automationml.org) has developed the Automation Markup Language (AutomationML ${ }^{\mathrm{TM}}$ ) as an intermediate standardized format for the digital factory. All these standardization efforts could help in obtaining real-time status information on manufacturing equipment. In the case study presented here, a customized, flexible interface was developed, since none of the selected manufacturing software provided a standard interface of this kind.

\subsection{Modeling issues and model building}

The simulation and calculation models used in the past (Heilala et al, 2010) either had capacity constraints or unlimited capacity depending on the objectives of the user. In the case of models with capacity constraints, the analysis shows when the order will be ready and how late it will be; it can also pinpoint the reason for late completion, such as a material shortage, an overload in manufacturing resources, and so on. In the latter case, unlimited capacity, the analysis shows the amount of resources needed in order to keep the customer promise, and the managers have the option to add relevant items such as human operators to critical manufacturing phases. Typically, final assembly that is dependent on manual labor can be analyzed with an unlimited capacity if human operators can be easily added when and where necessary. The model also checks the critical materials, i.e. stock values and ordered components, and indicates whether materials might run out at a certain point in the future.

Scheduling control strategies can be embedded directly into the simulation model or can be kept as a separate file, enabling users to adjust the parameters as necessary.

Automated model building from ERP data has also been developed and tested in the industrial pilot cases presented in the past with different simulation software (Heilala et al, 1999, 2001, 2007). Depending on the $3 \mathrm{D}$ visualization needs, manual input from a simulation engineer might be required. In general, the model and simulation load can start based on information such as:

- $\quad$ work orders (the order book from ERP database), the optional quotation book (from CRM or the sales offices), the production schedule

- $\quad$ product structure and routing, standard phase times

- work centers and component factories, layout, equipment capability

- stock items, buffers, material supply

- factory calendar, holidays, absences, planned maintenance, etc.

- equipment availability, efficiency

- simulation parameters: depth of product structure, work order release rules

- optional what-if analysis (machine breakdowns) and new orders, others. 


\section{Heilala, Montonen, Järvinen, Kivikunnas, Maantila, Sillanpää and Jokinen}

The other generic development point has been simulation data management. Simulation data is exported in pilot cases from ERP and other manufacturing information systems as formatted ASCII text and CSV files. The user interface incorporates tools to map the data fields of different source files in the simulation database data fields.

\subsection{Visualizing the simulation result}

Simulation analysis produces a great deal of numerical information such as tables, lists, and reports. However, it is difficult for a decision-maker to locate the relevant pieces of information. That is why normal operational users and production managers need tools for data mining. In addition, the simulation results have to be presented in a visually effective way to speed up and improve the way the results will be understood. The principles of Visual Analytics (Järvinen et al, 2009) are useful when developing the user interface.

Different users require, or are allowed access to different types of information; in other cases, the same information is presented differently to different users. For instance, a line supervisor and plant manager rely on different levels of data to make their business decisions - too little or too much data and its utility is diminished, if not lost. Time is an important factor in defining how much and what kind of data should be aggregated for the upper levels of the organization; a manager cannot afford to be "swimming in data" when a quick decision needs to be made (Heilala et al. 2001, 2007).

The system provides a proposal for rescheduling production orders by showing late or early orders and overloaded resources. The user can change the control and routing strategies and add resources to overloaded workplaces, by adding more human operators, increasing working hours or using subcontractors. The user can reschedule orders; change batch sizes and so on with the visual interface and has the option of re-running the simulation to check the results.

\section{APPLICATION BUILDING GUIDELINES}

The tool concept created during the development projects done in the past can be adapted for different companies. The building of each application is still a project: that requires a resource commitment from both the developers and the end-user. Application set-up is simple within an enterprise if all IT systems are the same; it is just a question of configuration. This has been evaluated and tested in past cases.

A typical simulation project is described in many simulation textbooks, for example, that of Banks et al. (1996). Now the aim is to create an integrated simulation application for manufacturing personnel. This project is more challenging. The application requires data from various other manufacturing information systems. Furthermore, the human aspect - user interaction with the planned system - must be carefully developed.

Based on earlier development tasks at VTT, including the guidelines from enterprise-application integration (Linthicum 2000), simulation project steps (Banks et al. 1996, Banks 1998) and the user-centered design principle (Vilpola and Terho, 2008; ISO 13407 standard; Sears and Jacko 2009), the following procedure has been drafted for application building. These activities should be considered during the development and implementation of operational simulation applications.

The ten steps in application building are (this is not a comprehensive list):

1. Defining the needs with the end-users.

2. Defining the business processes and work methods.

3. Specifying data and file structures, making sense of the data.

4. Collecting and creating data, interface methods.

5. Specifying the graphical user interface, visualization, user-centric design.

6. Programming the graphical user interface.

7. Implementing changes to the simulation and calculation model.

8. Testing and validating the model and system. 


\section{Heilala, Montonen, Järvinen, Kivikunnas, Maantila, Sillanpää and Jokinen}

9. Integrating the application into the ERP or MRP system and other legacy systems.

10. User training and documentation.

The first steps are critical for successful implementation. These steps are needed to gather requirements. The input of the end user is essential. End user resources are also required in testing and system validation. This is an iterative and parallel development process.

Understanding the enterprise and problem domain, steps 1 and 2: This is one of the most complex and time-consuming parts of the process. Understanding the problem domain requires working with many organization and department heads in order to get a handle on the structure and content of the various information systems, as well as to determine the business requirements of each organization. This process is basically about gathering requirements. Interfacing with paper, people, and systems are necessary to determine the information that will allow the problem to be defined correctly so that it can be analyzed, modeled and refined.

Making sense of the data, steps 3 and 4: The data-level implementation is about understanding where the data exists; gathering information on the data, and applying business principles to determine which data flow where, and why. There are basic sub-steps that must be followed:

1. Identifying the data.

2. Cataloguing the data.

3. Building the enterprise manufacturing metadata models.

4. Defining the interfaces between systems.

User-centric development, step 5: The specification of the graphical user interface is challenging. Other challenges include managing simulation data, effective visualization and reporting as well as user interaction with the system. The development team should apply a user-centric design methodology (Vilpola and Terho, 2008; ISO 13407:1999 standard; Sears and Jacko 2009). This means keeping the planned end-users in the development loop. User feedback is essential during development. The success of the system depends on how easy it is to use; the development of the user interface is thus a key factor.

The other steps: The steps can be done parallel to simulation modeling and graphical user interface development. The development of the graphical user interface and the adaptation of the simulation and calculation model are also demanding; these are based on the requirements collected in steps 1-5. The importance of validation and testing must never be underestimated, as they usually take a significant amount of time. The users must be able to rely on the data and information provided by the system.

\section{CASE STUDY - FAUCET MANUFACTURING}

VTT has developed a simulation-based decision support system for manufacturing with Oras Ltd. (www.oras.com). Oras Ltd. develops, manufactures and markets faucet systems and related valves and modules. The Oras Group is a family-owned corporation founded in 1945. The company relies on decades of experience in designing faucets in a variety of materials; in addition, it makes use of expertise in software and hardware when developing and manufacturing its products. The Oras Group has production plants in Finland, Poland, and Norway. The typical faucet manufacturing process is shown in Figure 4. The process flow is simplified; for example, temporary storage and parallel resources are not shown. One of the challenges in manufacturing is related to grinding and polishing, due to high surface quality requirements. There are automated and manual process phases in production. 


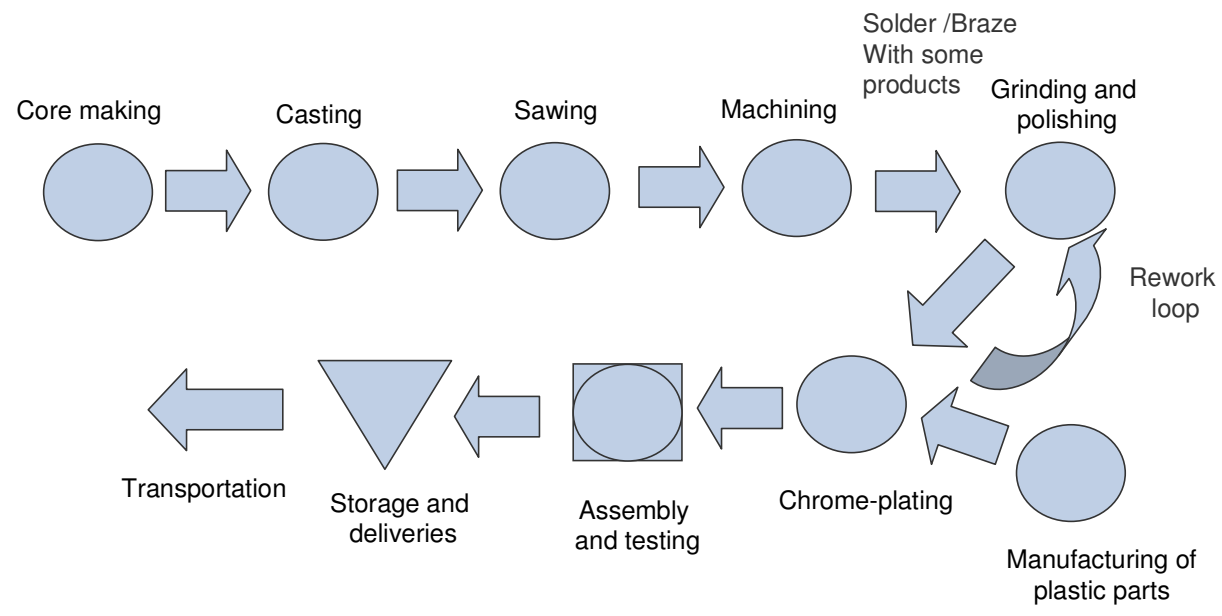

Figure 4: The main manufacturing processes in faucet factory.

The company produces a wide variety of products; often the same casting is used, though the final product can be different depending on machining. There are many information systems and one development challenge was to identify the data sources and develop the interface to the simulation system (Figure 5). One of the design principles involves using a single system for data updates, even if the data are used in other systems; for example, the maintenance system was responsible for the factory calendar, which displayed maintenance jobs and other machine breaks. The transfer file from ERP is created automatically early on every working day and read to the GESIM system. During night the status file is fed back to ERP system before initiation of updated demand calculation (see Figure 7).

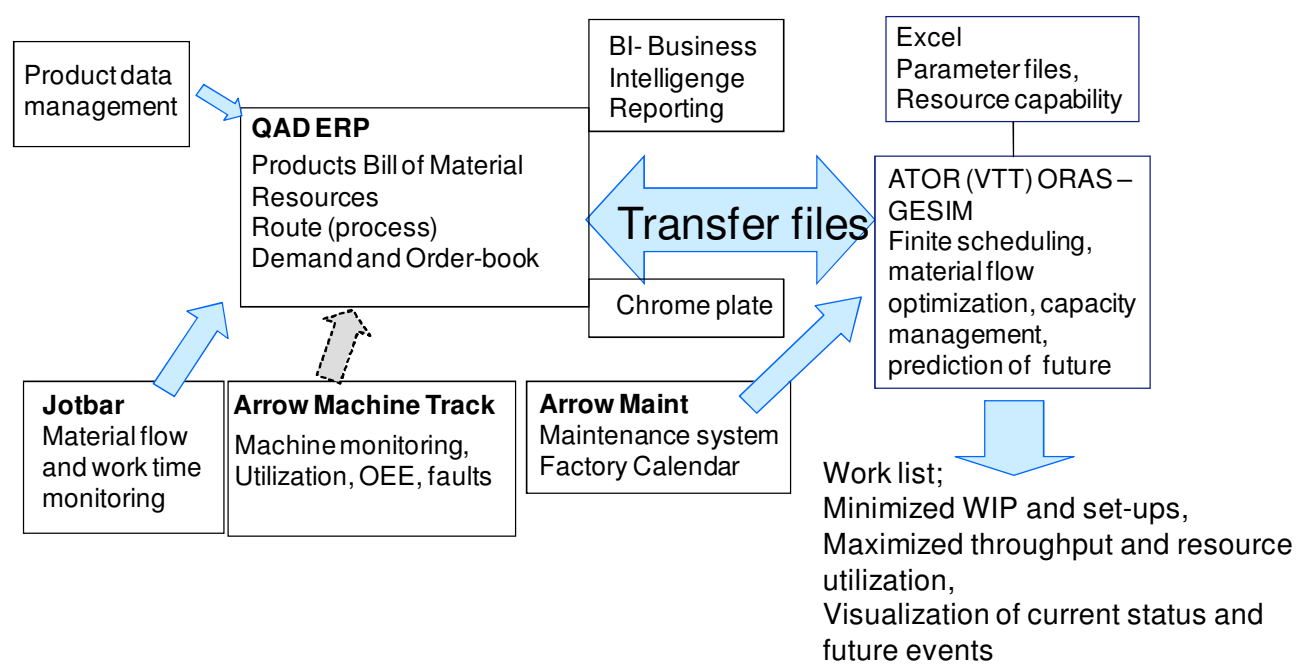

Figure 5: Heterogeneous manufacturing information systems. 


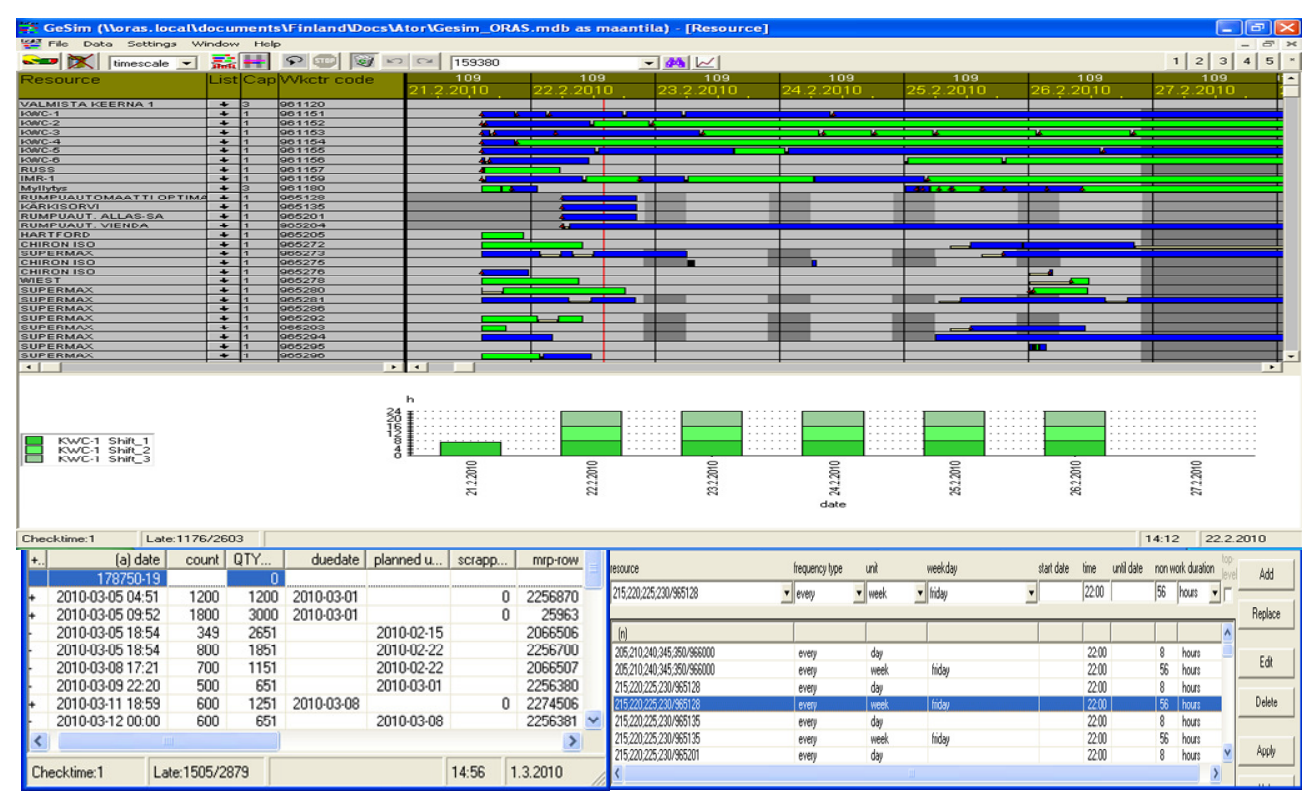

Figure 6: The user interface consists of a Gantt chart order view, a bar chart resource view and various reporting windows.

GeSIM software is installed on a server, and there will be multiple users, e.g. production managers and department supervisors. Some of the users can be classified as temporary users and some other daily users. Thus developing the user interface was challenging. The objectives and principles of user interface development were the following (see Figure 6):

1. Ease to use - readability and visualization. Main window with as little text as possible. The symbols and colors have been selected with care.

2. The main window shows the overall status of production and the accepted and proposed orders as a Gantt chart. The load at a selected work center can also be visualized. The auxiliary functions in the user interface are done using buttons, a mouse, pop-up windows and so on. Some of the features can be customized by the user.

3. Visualization was enhanced with colors, symbols and screening techniques. Depending on the task the user is doing, the colors are useful i.e. in showing alternative resources. The critical path of the work order can also be shown.

The scope of GESIM use is shown in Figure 7. GeSIM first reads the ERP demand calculation data (the proposal and accepted orders) and combines them with information on resource availability from maintenance information system. Software goes through all components that need to be manufactured and their routing and calculates the capacity needs. The results can be visualized by users, who can modify scheduling and routing, split batch size and also change the order status. The systems show which user is making changes and which user has locked the database. All users can visualize changes to the demand and capacity allocation calculation and see the name of the person who has entered the changes. 
Heilala, Montonen, Järvinen, Kivikunnas, Maantila, Sillanpää and Jokinen

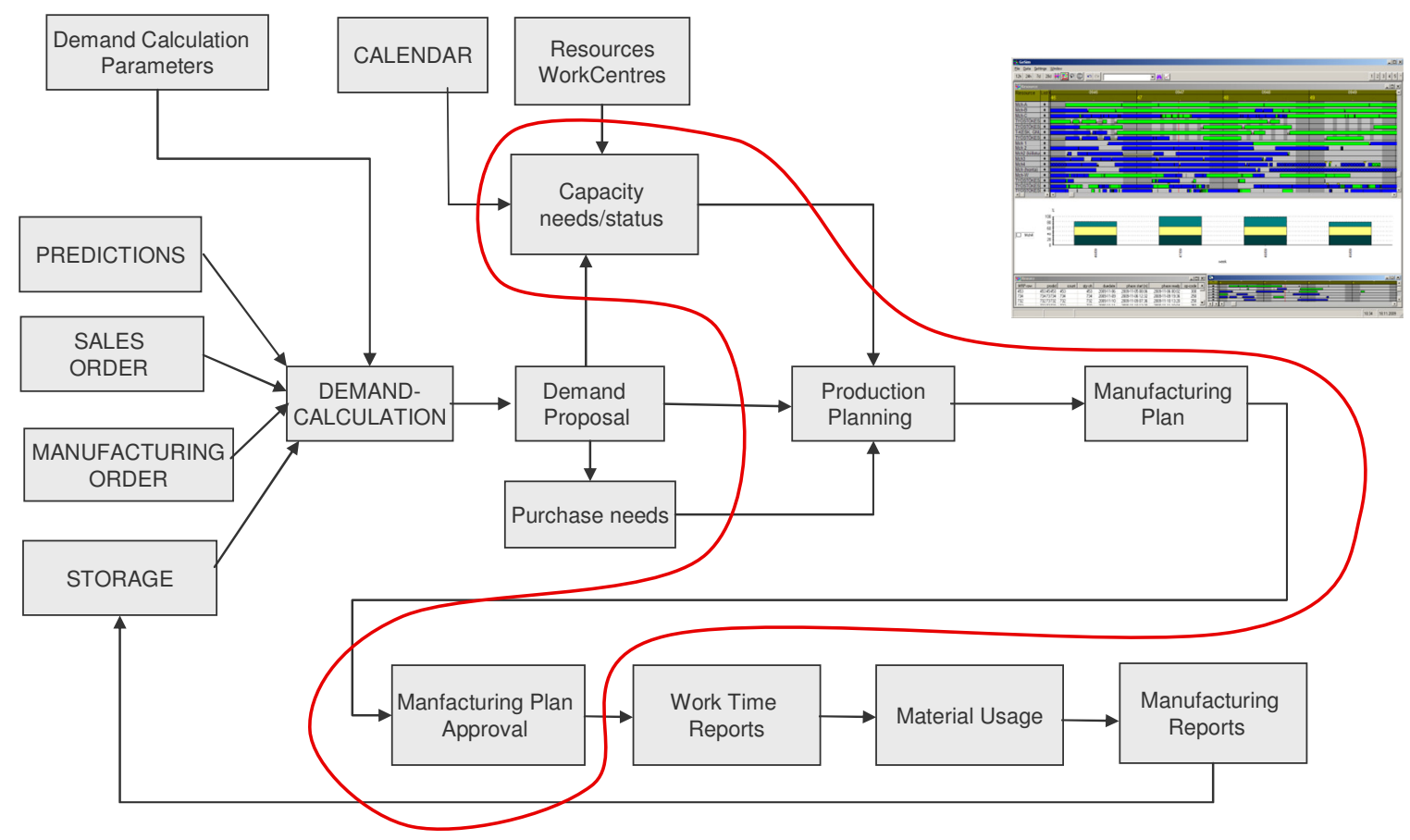

Figure 7: Production planning and management with GeSIM.

\section{SUMMARY}

The authors have developed several simulation-based decision support systems (DSS) for customerdriven manufacturing. Some of the earlier examples are shown in Heilala et al. (1999, 2001, 2007, 2010). The developed tool, GeSIM, is useful in customer-driven manufacturing because it adds features for production planners and capacity managers that have not been provided by standard tools in the past. By integrating discrete-event simulation and traditional production planning methods, it is possible to forecast the required workloads with given input values. The simulation model and the developed graphical user interface make it possible to visualize the occurrence of potential bottlenecks or other production problems and to take corrective actions.

The solution uses data from other manufacturing ICT systems and parameters provided by decisionmakers to help analyze future production situations and also plan corrective actions. The presented methodology does harmonize the decision-support system for production and capacity management and uses near real-time production status information. This type of operational decision support system has many potential users, from operators on the production line to the plant manager and even upper management:

- Production management, supervisors and planners: production scheduling, material handling, logistics, assembly, capacity optimization, orders, proactive planning and problem solving

- Production development engineers: planning changes or new systems

- Manufacturing operators: early information on upcoming work

This article presented also the development steps for a customized simulation-based decision support system. The user-centered design approach was applied for the development. Many users from the industrial partner participated in the development and user requirement specification. Initial usability studies show, that user involvement increases quality and ease of use. The developed tool, VTT GeSIM, can be adapted for new industrial fields and implemented for other enterprises. The developers must have a pro- 


\section{Heilala, Montonen, Järvinen, Kivikunnas, Maantila, Sillanpää and Jokinen}

found understanding of the processes of the field in question in order to be able to model the specific features of the industry. Naturally, modifications to the user interface and data interface are required. Both the end-user and system developer must commit development resources to the implementation project.

Sustainable production means developing efficient, environmental friendly production systems and also running operations efficiently. The GeSIM solution presented here aims to increase of the operational efficiency of production. Future research could concentrate on the use of new optimization parameters, such as energy consumption and also other environmental aspects. The improvement of environmental aspects in the system design phase has been presented by Heilala et al. (2008). The next step would be to also use these parameters for production scheduling decisions.

\section{ACKNOWLEDGMENTS}

The research was carried out as part of the national research project "Optimization of autonomous production cell - real time production intelligence" (2009-2010). The industrial partners, VTT and TEKES (the Finnish Funding Agency for Technology and Innovation) have funded the work carried out by VTT. The project was part of the national SISU 2010 - Innovative Manufacture program.

\section{REFERENCES}

Appelqvist, P., and J. -M. Lehtonen. 2005. Combining optimisation and simulation for steel production scheduling. Journal of Manufacturing Technology Management, Vol. 16, No. 2, pp. 197-210, ISSN: 1741-038X

Banks, J., J. S. Carson, and B. L. Nelson. 1996. Discrete-Event System Simulation (2nd ed.), Prentice Hall, ISBN 0132174499, Upper Saddle River, N.J.

Banks, J. (ed) 1998. Handbook of Simulation. Principles, Methodology, Advances, Applications, and Practice. John Wiley \& Sons, ISBN 978-0-471-13403-9, New York.

Fowler, J. W., and O. Rose. 2004. Grand Challenges in Modeling and Simulation of Complex Manufacturing Systems. SIMULATION, Vol. 80, No. 9, pp. 469-476

Heilala, J., J. Montonen, T. Salonen, E. Sorvali, and J. Suuronen. 1999. Simulation Based Operations Planning In Make-To-Order Manufacturing. 15th International Conference on Production Research (ICPR-15) "Manufacturing for a Global Market". Limerick, IR, 9 - 12 August 1999. University of Limerick, pp. 1467 - 1470.

Heilala, J., M. Hentula, J. Montonen, J. Alhainen, P. Voho, J. Salo, K. Kuokkanen, K. Leivo, and J. AliRaatikainen. 2001. Simulation aided decision support for customer driven manufacturing. 16th International Conference on Production Research (ICPR-16). Prague, Czech Republic, 29 July - 3 August 2001

Heilala, J., J. Montonen, A. Salmela, and P. Järvenpää. 2007. Modeling and Simulation for Customer Driven Manufacturing System Design and Operations Planning. Proceedings of the 2007 Winter Simulation Conference. S. G. Henderson, B. Biller, M.-H. Hsieh, J. Shortle, J. D. Tew, and R. R. Barton, eds. Washington D.C. 9-12 December, 2007.

Heilala, J., S. Vatanen, J. Montonen, H. Tonteri, B. Johansson, J. Stahre, and S. Lind. 2008. SimulationBased Sustainable Manufacturing System Design. Proceedings of the 2008 Winter Simulation Conference. S. J. Mason, R. R. Hill, L. Mönch, O. Rose, T. Jefferson, J. W. Fowler (eds.). IEEE, ss. 1922 1930

Heilala, J., J. Montonen, P. Järvinen, and S. Kivikunnas. 2010. Decision Support Using Simulation for Customer-Driven Manufacturing System Design And Operations Planning. Book Chapter in Decision Support Systems, Advances in, edited by: Ger Devlin. ISBN:978-953-307-069-8

Hindle, K., and M. Duffin. 2006. Simul8-planner for Composites Manufacturing. Proceedings of the 2006 Winter Simulation Conference. 


\section{Heilala, Montonen, Järvinen, Kivikunnas, Maantila, Sillanpää and Jokinen}

IMTI 2003. Roadmap Modeling and Simulation for Af-fordable Manufacturing”, January 2003, (http://www.imti21.org/resources/roadmaps.html)

ISO 13407 1999. Human-centred design processes for interactive systems. International Organization for standardization

Johansson, M., S. Leong, Y. T. Lee, F. Riddick, G. Shao, B. Johansson, A. Skoogh, and P. Klingstam. 2007. Generic Simulation of Automotive Assembly for Interoperability Testing, In Proceedings of the 2007 Winter Simulation Conference, eds. S. G. Henderson, B. Biller, M.-H. Hsieh, J. Shortle, J. D. Tew, and R. R. Barton, 1035-1043, Piscataway, New Jersey: Institute of Electrical and Electronics Engineers, Inc.

Järvinen, P., K. Puolamäki, P. Siltanen, and M. Ylikerälä. 2009. Visual Analytics. Final report. Espoo, VTT. 45 p. VTT Working Papers; 117. http://www.vtt.fi/inf/pdf/workingpapers/2009/W117 .pdf

Kádár, B., A. Pfeiffer, and L. Monostori. 2004. Discrete event simulation for supporting production planning and scheduling decisions in digital factories. Proceedings of the 37th CIRP International Seminar on Manufacturing Systems; Digital enterprises, production networks, Budapest, Hungary, 444448.

Kibira, D., and C. McLean. 2007. Generic Simulation of Automotive Assembly for Interoperability Testing, In Proceedings of the 2007 Winter Simulation Conference, eds. S. G. Henderson, B. Biller, M.H. Hsieh, J. Shortle, J. D. Tew, and R. R. Barton, 1035-1043. Piscataway, New Jersey: Institute of Electrical and Electronics Engineers, Inc.

Linthicum, D. S. 2000. Enterprise application integration. Addison-Wesley Longman Inc. ISBN 0-20161583-5, Reading, MA.

McLean, C., and S. Leong. 2001. The Expanding Role Of Simulation In Future Manufacturing. Proceedings of the 2001 Winter Simulation Conference. available http://www.informssim.org/wsc01papers/203.PDF

McLean, C., S. Jain, F. Riddick, and Y. T. Lee. 2007). A simulation Architecture for Manufacturing Interoperability Testing In Proceedings of the 2007 Winter Simulation Conference, S. G. Henderson, B. Biller, M.-H. Hsieh, J. Shortle, J. D. Tew, and R. R. Barton, eds. Piscataway, New Jersey: Institute of Electrical and Electronics Engineers, Inc.

Power, D. J. 2010. DSSResources.COM, URL http://DSSResources.COM, accessed 7 April, 2010.

Riddick, F., and Y. T. Lee. 2008. Representing Layout Information in the CMSD Specification, In Proceedings of the 2008 Winter Simulation Conference, eds. S. J. Mason, R. R. Hill, L. Mönch, O. Rose, T. Jefferson, and J. W. Fowler, Piscataway, New Jersey: Institute of Electrical and Electronics Engineers, Inc.

Sears, A., and J. A. Jacko. (eds) 2009. Human-Computer Interaction: Development Process. CRC Press 2009. ISBN: 9781420088908, Boca Raton, FL

SISO 2009. Pending standard: Core Manufacturing Simulation Data: UML model, SISO-STD-008-2009. CMSD Product Development Group, Simulation Interoperability Standards Organization. Available at http://www.sisostds.org/index.php?tg=fileman\&idx=list\&id=49\&gr=Y\&path=Specifications [accessed March 18, 2010]

Skoogh, A. 2009. Methods for Input Data Management - Reducing the Time-Consumption in Discrete Event Simulation. Research series from Chalmers University of Technology, Department of Product and Production Development: report, ISSN 1652-9243; nr 44.

Thompson, M. B. 1993. The Marriage between Simulation \& Real-time Control. APICS - The performance advantage. 8:43-46.

Vasudevan, K. K., R. Lote, E. J. Williams and O. Ulgen. 2008. Iterative Use Of Simulation And Scheduling Methodologies To Improve Productivity. Proceedings of the 2008 Winter Simulation Conference. S. J. Mason, R. R. Hill, L. Mönch, O. Rose, T. Jefferson, J. W. Fowler eds.

Vilpola, I., and K. Terho. 2008. Efficiency to manufacturing information systems - end-user involvement in the specification. In Finnish: Tehokkuutta tuotannon tietojärjestelmiin - loppukäyttäjät mukaan määrittelyyn. Teknologiateollisuuden julkaisu 5/2008. ISBN 978-951-817-992-7. 
Yoon, H. J., and W. Shen. 2006. Simulation-based real-time decision making for manufacturing automation systems: a review. Int. J. Manufacturing Technology and Management, Vol. 8, No. 1/2/3, pp.188-202

\section{AUTHOR BIOGRAPHIES}

JUHANI HEILALA, M.Sc (Mechanical Engineering) is a Senior Research scientist at VTT Technical Research Centre of Finland. He has 20 years of experience in production system development using simulation technology. One of his current research interests is expanding simulation and modeling from system design and analysis methods to simulation-based manufacturing operation planning. $\mathrm{He}$ also researches the integration of production system simulation with other analysis methods as well as sustainable manufacturing. His e-mail address is <juhani.heilala@vtt.fi $>$.

JARI MONTONEN is a simulation and software development expert at VTT. He has 20 years of experience developing software for specific areas of manufacturing environments, such as machine maintenance, worker ergonomics and simulation-aided planning and scheduling systems. In addition, he has over 15 years of experience in production system simulation, having carried out dozens of simulation-aided analyses of production systems for companies in many branches of industry. His e-mail address is $<$ jari.montonen@vtt.fi>.

SAULI KIVIKUNNAS, M.Sc (Process Control Engineering) is a Research Scientist at VTT. He has over 10 years of expertise in developing production control systems in process industries. His research interests range from process information integration to holistic process performance management with a systemic and ICT perspective. He has served VTT and the industry by managing projects in the fields of process diagnostics, process performance analysis, and adaptive user interfaces in process automation and ICT solutions for ubiquitous environments His e-mail address is <sauli.kivikunnas@vtt.fi>.

PAULA JÄRVINEN, M.Sc. (Information management) is a Senior Research Scientist at VTT. Her professional experience includes software engineering, requirements definition, data modeling, user interfaces, and project management. Her current research interests include information visualization, visual analytics, web user interfaces, and usability and information management. Her e-mail address is <paula.jarvinen@vtt.fi>.

MATTI MAANTILA is a project manager of the supply chain at Oras Ltd. Rauma Factory. He has been working at Oras for 26 years. He started in product design and customer service, and later became responsible for various production development and production management tasks. More recently, he has been working as a supervisor and production manager. He has been in Poland for the past for years at the Oras Olesno factory. His e-mail address is<matti.maantila@oras.com>.

JARKKO SILLANPÄÄ is a production foreman Oras Ltd. Rauma Factory. He is responsible for the supervision and planning of component manufacturing in the grinding and polishing department. His e-mail address is<jarkko.sillanpaa@oras.com>.

TERO JOKINEN has worked as a tactical planner at Oras Ltd. since August 2009. He is responsible for site management, demand calculation, full-scale implementation and development as well the production and order planning of the Oras Group. Previously he worked in the Finnish paper industry as a production planner. His e-mail address is<tero.jokinen@oras.com>. 